Cahiers de recherches médiévales

\title{
Force ou violence?
}

Images de Jules César dans l'œuvre de la Pléiade

\section{Édith Karagiannis-Mazeaud}

\section{(2) OpenEdition \\ Journals}

Édition électronique

URL : https://journals.openedition.org/crm/2563

DOI : $10.4000 / \mathrm{crm} .2563$

ISSN : 1955-2424

Éditeur

Honoré Champion

Édition imprimée

Date de publication : 30 juin 2007

Pagination : 85-110

ISSN : 1272-9752

Référence électronique

Édith Karagiannis-Mazeaud, «Force ou violence? », Cahiers de recherches médiévales [En ligne], 14 spécial | 2007, mis en ligne le 30 juin 2010, consulté le 15 décembre 2022. URL : http://

journals.openedition.org/crm/2563; DOI : https://doi.org/10.4000/crm.2563 


\section{酷M}

\section{Force ou violence? Images de Jules César dans l'œuvre de la Pléiade}

Durant la seconde moitié du XVI ${ }^{\mathrm{e}}$ siècle, les images de Jules César et les travaux le concernant se multiplient autour du roi de France. Dans les Entrées, César est encore l'un des neuf Preux ${ }^{1}$ et, depuis Les Commentaires de la guerre gallique de François Demoulins et Godefroy le Batave offerts après Marignan à François Ier "second César subjugateur des Helvétiens »², le rapprochement entre le vainqueur romain et le souverain français est largement exploité dans les textes et dans les arts figuratifs. Quelques portraits suffisent à en témoigner, que l'on songe au François Ier en Jules César de Primatice (fig. 1) ${ }^{3}$ destiné aux armoires du Cabinet du roi à Fontainebleau où il était couplé à La Force, ou encore à la figure du roi dans L'Ignorance chassée peinte par Rosso vers 1535 à la Galerie François Ier, largement diffusée par l'estampe : le roi lauré, vêtu à la romaine, brandit l'épée de la main droite tandis qu'il tient un livre sous le bras gauche (fig. 2) ${ }^{4}$. Appuyé sur la revendication à l'Empire fondée sur la formule Rex imperator in suo regno adoptée au temps de Philippe le Bel, ce succès s'éclaire notamment par la rivalité avec Charles Quint $^{5}$ : après son élection, ce dernier construit lui aussi son image sur celle de Jules César victorieux ${ }^{6}$.

\footnotetext{
${ }^{1}$ Par exemple, lors de l'Entrée en Avignon de Charles IX, le 24 septembre 1564, Jules César figure au nombre des neuf preux qui l'accueillent et le choisissent pour dixième preux, puisque, comme le dit un sonnet qui lui est adressé, «en ce rond Cesar surpasserez », The Royal Tour of France by Charles IX and Catherine de'Medici 1564-1566, Toronto, Buffalo, London, U. of Toronto Press, 1979, p. 229 et 231. Pour la première moitié du siècle, voir P. Gringore, Les entrées royales à Paris de Marie d'Angleterre (1514) et de Claude de France (1517), éd. Cynthia J. Brown, Genève, Droz, 2005, p. 168.

${ }^{2}$ Voir Anne-Marie Lecoq, François Ier imaginaire. Symbolique et politique à l'aube de la Renaissance française, Paris, Macula, 1987, chap. VII, passim ; Cécile Scailliérez, François Ier par Clouet, Paris, RMN, 1996, p. 19-24.

${ }^{3}$ Primatice, François Ier en César, dessin préparatoire pour le Cabinet du roi à Fontainebleau, 0,220x , v. 1540 ?, Chantilly, Musée Condé, Inv. 153 (135g).

${ }^{4}$ RÉné Boyvin, L'ignorance vaincue, d'après Rosso. Burin, 275x418 mm, détail. Bnf, Est., Ba 12 in-folio.

${ }^{5}$ À la suite du triomphe d'Alphonse V d'Aragon à Naples (1443) organisé directement d'après le De Bello gallico, du «culte » de Jules César développé par la famille d'Este et de la diffusion par la gravure, dans toute l'Europe, des neuf tableaux glorifiant Les Triomphes de César peints par Mantegna de 1486 à 1492 à partir de la bibliothèque des Gonzague à Mantoue et de sources iconographiques antiques. Voir Françoise Siguret, Les fastes de la Renommée. XVI et XVII siècles, Paris, CNRS, 2004, p. 110-111; J. Burckhardt, La civilisation de la Renaissance en Italie, V, 8, trad. H. Schmitt, éd. R. Klein, Paris, Le Livre de Poche, 1988, 2 vol., t. II, p. 388. Rappelons également qu'on représente les triomphes de Jules César en 1501, à Rome, à l'occasion du mariage d'Alphonse d'Este et de Lucrèce Borgia.
}

Cahiers de Recherches Médiévales, 14spé, 2007 
Les descendants de François Ier reprennent cette figure dans leur propre iconographie. Jules César se trouve à cette époque exalté, outre les textes anciens, par les travaux d' «antiquaires» ou d'italianisants proches de la cour tels Gabriel Simeo$\mathrm{ni}^{7}$ et par les collections numismatiques: tandis que s'organisent les collections royales, de grands collectionneurs publient et commentent les médailles, dans le sillage du De Asse. Dans l'ouvrage De la Religion des anciens Romains publié par Du Choul en 1566, Jules César occupe une place importante. A priori, ce personnage emblématique ne peut donc qu'intéresser les poètes de la Pléiade : il semble parfaitement convenir aux discours encomiastiques ou parénétiques adressés au roi ou aux grands capitaines le représentant sur le champ de bataille.

Pourtant deux constatations corrélatives s'imposent d'emblée. Tout d'abord, dans ce corpus, la figure de Jules César est beaucoup moins fréquente que celle d'Auguste, «le fils de César ${ }^{8}$ associé à l'Age d'or, "Prince guerrier, ensemble Prince juste ${ }^{9}$, ou même que celles de Pompée et de Scipion. En revanche, elle suscite davantage de discussions et de réflexions d'ordres divers, linguistique et poétique tout autant que politique et moral. Ensuite, le discours sur César se construit à partir des sources très variées, principalement de réminiscences du De Bello gallico avec, ici et là, ses mots célèbres ${ }^{10}$, dont certains déjà recueillis et commentés

Voir Roy Strong, Les fêtes de la Renaissance (1450-1650), trad. B. Cocquio, Arles, Solin, 1991, p. 86-88.

${ }^{6}$ Par exemple, des effigies de César, accompagnées de celles de Scipion, Hannibal, Alexandre, ou d'Auguste, Vespasien et Trajan, sont chargées de signifier son imperium lors de ses entrées solennelles dans les villes de Bologne en 1529, de Naples en 1535. Voir R. Strong, op. cit., p. 157.

${ }^{7}$ Voir, entre autres, le Cesar renouvelé par les observations militaires du S. Gabriel Symeon, Paris, V. Sertenas, 1558 et l'emblème «Pour un grand seigneur» repris à P. Giovio : la vignette représente Jules César brandissant de la main droite le glaive, de la gauche le livre, debout sur le globe terrestre, avec la devise Ex utroque Coesar. En dessous, le texte est le suivant: «Un grand Seigneur me demanda un iour, quelle Devise il pourroit porter pour donner à entendre au monde qu'il avoit grande envie, et cherchoit tous les moyens d'estre encore plus grand et puissant que les autres. Parquoy ie luy en baillay une d'un Empereur armé avec sa couronne de laurier en la teste, tenant d'une main un livre, et de l'autre un'espee, et luy estant debout sus un globe de la terre avec ces paroles : EX UTROQUE CÆSAR . Voulant signifier que par le moyen des lettres et des armes, et estant tousiours debout, et prest à entendre ses affaires, Iule Cesar devint Seigneur de tout le monde. ", Les devises ou emblemes heroïques et morales inventées par le s. Gabriel Symeon, Lyon, G. Rouillé, 1559, p. 16-17.

${ }^{8}$ Ronsard, sonnet II «A lui-mesme», v. 14, «Sonnets à diverses personnes », Euvres Complètes, éd. J. Céard, M. Simonin, D. Ménager, Paris, Gallimard, Bibliothèque de la Pléiade, 2 vol., t. I, 1993, t. II, 1994, I, p. 470. Toutes les références renvoient à cette édition. ${ }^{9}$ Ronsard, «La Lyre », v. 242, Le Premier Livre des Poemes, t. II, 1994, p. 694.

${ }^{10}$ Voir par exemple le poème «A Ian Dorat», v. 13-24, où Baïf s'appuie sur le mot de César «J'aimerois mieux estre icy le premier, que le second à Rome » (Plutarque, César, XI), Tiers Livre des Poemes, in Euvres Complètes, I, Euvres en rime. Première Partie, Neuf livres des poemes, éd. dir. J. Vignes, Paris, Champion, 2002, désormais appelé $O C$, t. I, p. 252. 
par Érasme ${ }^{11}$, mais également à partir de Plutarque et de la traduction par Amyot des Vies parallèles $^{12}$, de Lucain, Cicéron, Tite-Live, parfois Suétone et Virgile ou encore Appien, dont les Guerres des Romains Livres IX (...) et Cinq des guerres civiles traduites par Claude de Seyssel sont maintes fois rééditées à partir de $1544^{13}$. Dans quelle mesure, donc, les poètes de la Pléiade font-ils chorus avec la cour et comment retravaillent-ils l'image de Jules César? Telles sont les questions auxquelles, sans prétendre à l'exhaustivité ${ }^{14}$, nous voudrions tenter ici d'apporter quelques éléments de réponse.

\section{Langue et imperium}

Au temps où, à la politique de François Ier en faveur de la langue française, s'ajoute celle résumée par la devise Donec totum impleat orbem, César intéresse les poètes en tant qu'exemple historique exceptionnel de l'immense pouvoir dont peut jouir «la Royauté (...) mestier actif ${ }^{15}$ lorsqu'elle est fondée sur la réunion de capacités personnelles de deux ordres présentés comme solidaires et mobilisant réflexion et action: d'une part, militaire et politique, d'autre part, littéraire au sens large du terme. César «monarque du monde » apparaît comme le paradigme de la puissance temporelle et de la gloire obtenues par les œuvres, militaires, civiles, discursives, pérennisées par «l'encre qui combat/Contre la faulx du Temps qui toute chose abat $»^{16}$, qu'il s'agisse de son propre discours ou de ceux qu'il a engendrés. Aussi constitue-t-il un argument particulièrement persuasif du plaidoyer en faveur de l'efficacité et de la grandeur du langage et les poètes scrutent-ils ses intentions, ses choix et ses méthodes comme autant de points à imiter, à faire imiter et, si possible, à dépasser.

Il leur paraît donc important de rendre à César, en français, toute l'ampleur de sa stature. Ce soin transparaît à travers des détails témoignant aussi de la qualité humaniste des transpositions de Peletier et de son souci du lecteur. Là où Horace évoque simplement l'aménagement des ports, digne d'un roi, le poète, s'appuyant sur Plutarque, introduit le nom de César:

Ce qui fut terre ferme,

Est maintenant tout propre au navigage

De $\operatorname{par}^{\text {César }}{ }^{17}$.

\footnotetext{
${ }^{11}$ Voir par exemple «Veni, vidi, vici $»$ dans les Apophtegmes, IV, 12.

${ }^{12}$ Ed. princeps : 1558.

${ }^{13}$ Voir notamment les éditions de Lyon, A. Constantin, 1544 ; Paris, 1552 ; Galiot du Pré, 1554 ; 1560 ; M. Gadouillot, 1570 ; O. de Harsy, 1570 ; Buon, 1573 ; Gilles Beys, 1580.

${ }^{14}$ Nous avons laissé de côté Les Discours de Jules César avant de franchir le Rubicon de Jodelle, présentés par E. Buron dans La Figure de Jules César au Moyen Age et à la Renaissance, dir. B. Méniel et B. Ribémont, CMR 13/2006, p. 107 sqq.

${ }^{15}$ Ronsard, Le Quatriesme Livre de la Franciade, v. 1584, La Franciade, t. I, p. 1147.

${ }^{16}$ Ronsard, «L'Excellence de l'esprit de l'Homme, v. 91-92 », Le Second Livre des Poemes, t. II, p. 839 .

${ }^{17}$ L'Art Poetique d'Horace traduit en vers François par Jaques Peletier du Mans, Paris, Michel de Vascosan, 1545, p. 9 ro. Voir Horace, Ars poetica, v. 65 et Plutarque, Vie de César,
} 
Cependant, ce qui retient avant tout ces poètes, comme plus tard Montaigne ${ }^{18}$, c'est à la fois la qualité de la langue de César et l'exemple de l'auteur conscient des implications politiques de ses mots, de ses options linguistiques et stylistiques. La volonté d'illustration et de diffusion de sa langue naturelle qui marque son œuvre procède en effet de la même logique que celle d'extension de l'imperium politique, et elle a été partagée par d'autres grands Romains. Peletier du Mans le souligne dans l'Épître dédicatoire de 1545 à l'Art poëtique d'Horace: comme Cicéron qui donna lumière et dignité en même temps au latin et à la philosophie,

Iule Cesar qui fut monarque du monde n'avoit moindre solicitude et affection d'amplifier l'usance de sa langue que de dilater les fins de l'empire Rommain ${ }^{19}$.

C'est dans un esprit analogue qu'en 1549, la Deffense et Illustration de la langue françoise mentionne César dans la théorie des grands hommes politiques qui, avec poètes et orateurs, ont construit la gloire de Rome. L'autorité du paradigme est claire et Du Bellay ne manque pas d'ajouter que la France a également donné de tels exemples $^{20}$, même si, personnellement, il considère César comme relevant des sujets guerriers qu'il préfère laisser à d'autres ${ }^{21}$. En 1578 , Tyard reprend à son tour cette question dans l'épître à Henri III en tête du Second Curieux, où il évoque la difficulté de traiter en français de sujets intellectuels : avec Caton, Varron, Cicéron, Salluste, Virgile, Horace et Ovide, César compte au nombre des meilleurs auteurs latins parce qu' «ayant les sciences et la langue grecque à commandement», ils préfèrent composer en leur langue naturelle qu'en celle "acquise par laborieux et artificiel estude». Cette langue est remarquable par son elegantia que l'on souligne après Érasme $^{22}$, tout en précisant bien, comme Ronsard, héritier du Ciceronianus, à propos

§58-10 : » Il voulait (...) opposer des barrières à la partie de la mer la plus proche de Rome en élevant des digues et après avoir nettoyé la côte d'Ostie des obstacles cachés qui en rendaient l'accès difficile, y aménager des ports et des mouillages sûrs pour une si intense activité maritime », Vies parallèles, traduction R. Flacelière et E. Chambry, prés. J. Sirinelli, Paris, R. Laffont, coll. Bouquins, 2001, p. 186.

${ }^{18}$ Voir Essais, II, X, dans Euvres Complètes, éd. A. Thibaudet, M. Rat, Paris, Gallimard, Bibliothèque de la Pléiade, 1962, p. 396.

19 Épître dédicatoire à «Cretofle Perot Ecuier Seneschal du Maine», L'Art Poetique d'Horace, op. cit., p. 4.

${ }^{20}$ Voir La Deffence et Illustration de la Langue Françoyse, I, III, éd. H. Chamard, J. Vignes, Paris, STFM, 2000, p. 28.

${ }^{21}$ «Bella per Aemathios non hic civilia campos,/Fraternas acies, arma virumque cano», «Ad Venerem », v. 1-2, Amores, Euvres Poétiques, t. VII, Euvres latines : Poemata, traduction et édition G. Demerson, STFM, 1984, p. 135.

${ }^{22}$ Voir Tyard, Le second Curieux, in John Lapp, The Universe of Pontus de Tyard, Ithaca, New York, 1948, p. [129]. Voir également Erasme, Le plan des études (De ratione studii), traduction J.C. Margolin, in Erasme, éd. C. Blum, A. Godin, J.-C. Margolin, D. Ménager, Paris, R. Laffont, collection «Bouquins», 1992, p. 444. Ainsi Tabourot, admirateur également de Peletier, recommandera dans Les Bigarrures du seigneur Des Accordz, de faire commencer très tôt aux enfants l'apprentissage des langues, notamment du latin : il faut leur 
de Paschal, que l'imitation exclusive de César ou de Cicéron constitue une preuve d'incompétence ${ }^{23}$. Le De Bello gallico montre en effet que César s'est trouvé confronté à des questions stylistiques analogues à celles qui passionnent la Pléiade. Côté onomastique, il fournit arguments et solutions pour la transposition des noms propres étrangers en français. Peletier discute ce point en 1550 dans le Dialogue de l'orthographe et de la prononciation. D'un côté, dit-il, «vrei est qu'un nom propre se doit le moins desguiser que l'on peut », surtout quand ce nom procède d'une étymologie historique. C'est pourquoi,

(...) nous ne changerions pas le nom de Cesar qu'on dit lui avoèr étè donnè a cause qu'à sa nescance le vantre de sa mere fùt incisè ou ouvert ${ }^{24}$

De l'autre, Peletier considère que, pour assurer l'imperium du français, il convient de suivre la méthode de César: il faut franciser les noms propres étrangers contemporains lorsque c'est possible,

comme nous voions an Cesar quand il parle des nons de noz villes et de nos hommes Gauloes, qui lui etoént pour lors si barbares : e toutefoes il les à Latinizèz ${ }^{25}$.

Beaucoup plus tard, dans le De recta nominum impositione, publié en 1606, Tyard reprendra encore cette question de l'évolution et de la transposition des emprunts. Par leur célébrité, les Commentaires et leur auteur offrent à nouveau un idéal paradigme à qui se soucie d'exposer clairement et avec solidité une réflexion théorique sur la langue, son évolution et ses implications politiques et morales. Tyard choisit donc le mot «César» pour en retracer l'histoire, de son rapport à l'obstétrique à sa transformation en titre impérial dont les langues contemporaines ont hérité26. S'appuyant sur les fragments à cette époque attribués à Caton, il explique comment Ascagne, lors de sa victoire sur Mezentius, prit le surnom grec de

faire lire César, pour entretenir, notamment, «la beauté de la langue », Paris, J. Richer, 1583, p. $10 \mathrm{r}^{\circ}, 13 \mathrm{v}^{\circ}-14 \mathrm{r}^{\circ}$.

${ }^{23}$ [Petri Paschalii Elogium], Pièces latines, in Ronsard, Euvres complètes, éd. cit., t. II, p. 1216 et 1221.

${ }^{24}$ Dialogue de l'Orthographe e de la Prononciation Françoese, departi en deus livres par Iaques Peletier du Mans, Poitiers, E. de Marnef, 1550, p. 158-159.

${ }^{25}$ Ibid., p. 162.

${ }^{26}$ Quod genus nominationis vigente Reipub. Flore, aliis ob similes causas, imposuisse Romanos planum est. Sed postquam ad Imperatores, summa translata est potestas, in ampliorem copiam agnominationes excreverunt. Tantusque fuit primi C. Iulii Caesaris fauor : et C. Iluij Coes. Octauiani Augusti, eius adoptiui filij, et in Imperio successoris, tanta foelicitas, ut ad nostra usque tempora, et Coesaris et Augusti agnomina inter Imp. Romanos perdurarint : cum tamen primus, ut ab autoribus non malis scripto mandatum est (nec moror sitne de progenitore suo quodam, it intelligendum) à cceso, ut uivus nasceretur, matris utero : secundus vero ab admiranda foelicitate in augendo Imperio, et rebus amplissime summaque moderatione gestis, CAESAR et AUGUSTUS cognominati fuerint, De recta nominum impositione, A Ponto Tyardce Bissiano, Lyon, J. Roussin, 1603, p. $48-49$ (num. erronée 3839). 
Iolos, désignant la barbe qui lui naissait alors sur les joues ${ }^{27}$, origine du nom latin de la gens Iulia puis des Césars qui toutefois, loin de s'en contenter, en désirèrent une infinité d'autres, plus ambitieux les uns que les autres ${ }^{28}$.

Côté phonétique, Peletier se préoccupe également, en 1550, de juste prononciation, latine et française : «Iulius an Latin ne se doet pas sonner comme an Françoes la premiere de Iules $»^{29}$. Il y revient en 1556 dans le texte des Discours non plus melancoliques que divers qui lui est attribué, où il éclaire ce point d'un jour proprement humaniste liant à la fois langue, civilisation et esprit critique, politique : il considère les prononciations contemporaines du latin comme des distorsions, chacun appliquant à cette langue son propre accent, à commencer par les ecclésiastiques romains,

de sorte que si Jule Cesar trouvoit aujourd'hui Paul le tiers seigneur de sa Romme, disant la grand messe pour une feste de Saint Pierre, il ne l'entendroit guere mieux, que fait un Français ou un Espagnol l'Italien à la premiere rencontre ${ }^{30}$.

César ne résume pas, en effet, la brillante Rome antique par sa seule elegantia. Il la sert également en assurant la glorieuse mémoire de son extension territoriale. Cette geste antique fournit aux Français du $\mathrm{XVI}^{\mathrm{e}}$ siècle d'inestimables informations historiques sur ce que Peletier appelle de façon significative «nostre Gaule». Les leçons du passé instruisant le présent, le De Bello gallico constitue donc, par sa matiera aussi, un modèle à proposer à tout dux soucieux de l'avenir. Désireux que l'on écrive davantage de livres «en quelque langage que ce soit», Peletier souhaite d' " un Capitaine, qu'il face de beaus memoires de ses faits comme Cæsar ${ }^{31} \ll$ :

Nous n'avons pas grans nouvelles de ce qui a esté fait en nostre Gaule, devant que Iule Cæsar y vint. Si nos anciens ont fait des livres de leurs affaires, nous ne les avons, et quand nous les aurions, nous ne les entendrions : car ils parloient autre lan-

\footnotetext{
${ }^{27}$ Cato vero in Originum libris scripsit: Aenea et Turno pugna confectis, Ascanium et Mezentium certamine singulari concurisse : in quo, caeso Mezentio, Ascanius, quia Í́̉os, id est prima genarum lanugo, huius victorice tempore illi nascebatur, Iuli nomen coepit, ibid.

28 "Unde gens Iulia, è qua Iuliorum Caesarum origo defluxit. Sed adeo sequentium Imperatorum ambitiosa cognominationum, atque titulorum adoleuit cupido, ut usque ad fastidium lectorum et auditorum, multis cognominibus decorarentur. Quid, multis? Imo nimium multis, ne dicam infinitis : est enim istis adulatoriis credendum carminibus: Si petat a victis, tot sumet nomina Coesar,/Quot numero gentes maximus orbis habet, ibid. Ronsard évoque lui aussi les «Cesars, qui se vantoyent estre sortis d'Iüle fis d'Aenee » en considérant qu'il s'agit d'une legenda poétique. Voir «Preface sur la Franciade touchant le Poëme heroïque », La Franciade, Appendices, t. I, p. 1183.

${ }^{29}$ Ibid., p. 10.

${ }^{30}$ Discours non plus melancoliques que divers, Paris, E. de Marnef, 1556, p. 24. C'est nous qui soulignons.

${ }^{31}$ Ibid., p. 62.
} 
gage que cellui dont nous usons à ceste heure (...) Depuis Cæsar, (...) [nous] avons aussi fort peu des choses faites en ladite Gaule ${ }^{32}$.

\section{Le roi «imitateur du grand Cesar»}

Ainsi, dans l'esprit de la translatio studii et imperii, ce glorieux César dont le statut se voit, directement ou non, rapproché de celui de roi ou d'empereur ${ }^{33}$, contribue largement à faire de Rome le modèle de l'empire souhaité au roi de France. En 1544, dans une ode célébrant la naissance du dauphin, Ronsard émet le vœu que le «royal enfant/Qui doit commander à la France » puisse assurer sa propre gloire en

Imitateur du grand Cesar

Vaillant et sçavant tout ensemble,

Qui le jour dontoit les haineux,

Et la nuit escrivoit ses gestes ${ }^{34}$.

Les exceptionnelles qualités personnelles et militaires ayant permis les succès qui rangent César, avec Pyrrhus, Alexandre et Octave, au nombre des «plus vaillants Capitaines » et des «Rois [qui] ont fait leur gloire espandre/Par leurs combats au monde ${ }^{35}$ ne sont donc pas niées. Lorsque la convenance s'y prête, l'image de César vainqueur permet d'affirmer la valeur de l'époque contemporaine, égale voire supérieure à l'antiquité. Du Bellay attribue ainsi à Henri II « de Cesar la grand celerité ${ }^{36}$ et à «Pyrrhus Strozzi »sa vigilance ${ }^{37}$. Mais cette figure est surtout sollicitée dans les poèmes encomiastiques composés en l'honneur de la prise de Calais par François de Guise, en janvier 1558. Ordonnateur des fêtes organisées à Paris pour fêter cette victoire en février suivant, Jodelle fait peindre dans la salle de l'Hôtel de Ville,

(...) une vieille bannière Romaine representant une de celles de Jules Cesar (...) qui portait ces trois lettres d'or V.V.V., lesquelles comme chacun sçait assés, et comme il a esté chanté et rechanté par nos nouveaus poëtes, qui depuis naguiers ont si bien

\footnotetext{
${ }^{32}$ Ibid., p. 42-43.

${ }^{33}$ Ronsard parlera par exemple d' «Auguste second empereur » ou encore de «fils de César». Voir «Preface sur la Franciade (...)», op. cit., t. I, p. 1182 ; Sonnet 2 «A luy-mesme», v. 14, Sonnets à diverses personnes, t. I, p. 470.

${ }^{34}$ Ode XII «Sur la naissance de François, dauphin de France, fils du roy Henri II ${ }^{\mathrm{e}}$ », v. 7-8 et 31-34, Le Troisesme Livre des Odes, t. I, p. 761.

${ }^{35}$ Ronsard, «Hynne de l'Or», v. 371 et 375-376, Les Hynnes, II, t. II, p. 588.

${ }^{36}$ "Chanson», v. 36, Poésies diverses, STFM, V, p. 392, Dans cette déploration prêtée à Diane de Poitiers sur une absence de Henri II, Du Bellay dresse du roi un portrait «à la Pandore », lui prêtant aussi la hardiesse d'Alexandre, la dextérité d'Hannibal, la sagesse de Scipion.

${ }^{37}$ Avec le soin de Pyrrhus, l'intelligence statégique d'Alexandre, la patience d'Hannibal, le courage de Scipion ou de Marius. Voir (Tum. 37 a) «Pyrrhi Strozzæ», v. 5, Tumuli, Euvres Poétiques, t. VII, Euvres latines : Poemata, traduction et édition G. Demerson, STFM, 1984, p. 214-215.
} 
tenu chacun leur partie en la louange de ceste victoire, signifioit VENI, VIDI, VICI de $\mathrm{Cesar}^{38}$.

Une devise proclame alors la supériorité de Guise sur César. Jodelle le souligne : il en fournit la première version et explique comment il l'a remaniée :

Et pour autant que Monsieur de Guise n'a point esté en ceci d'un moindre bonheur, que celui la dont se vantoit ce Romain (...) il me vient (...) de metre (...) encore un $\mathrm{V}$ dedans la bande, et peignant une fortune garrotée de chaisnes de fer, avec ces vers (...):

hoc caesar mihi cede, tribus sit et addita quarta

littera, sors adversa meos et iniquia premebat

mox veni, vidi, vici : vinxi quoque victam ${ }^{39}$.

Dans cette mise en scène suscitée par l'enthousiasme de la victoire et réglée par le decorum, l'image de César accompagne les figures et topoi historiques ou moraux convenant au grand genre, notamment l'image Fortune vs Vertu. Mais au topos foelix ut Coesar des portraits « à la Pandore » de grands capitaines de la première moitié du siècle ${ }^{40}$, Jodelle préfère ici un César exemplum de la Vertu.

Dans l'«ode presentée à Monseigneur le duc de Guyse à son retour de Calais », Belleau qui a pris part à son infructueuse campagne d'Italie esquisse une stylisation de ce courage rejoignant, dans le domaine plastique, la terribilità d'un Michel-Ange ou d'un Giulio Romano dans la salle des Géants au Palazzo del Te, peinte en 1530 en l'honneur de la visite de Charles-Quint à Mantoue : dans le sens de la terribilità de Michel-Ange et des Géants de Giulio Romano qu'il a pu admirer au Palazzo del Te. Le poète réussit à tourner la difficile traversée des Alpes en démonstration de force de caractère de la part

D'un Cesar, se declarant

Sur l'ennemy conquerant.

D'un Cesar, dont le courage

En cent guerrieres façons

A fait sentir son orage

Et aux Rochers et aux Mons ${ }^{41}(\ldots)$

${ }^{38}$ Le Recueil des inscriptions, figures, devises et masquarades, ordonnées en l'Hostel de ville à Paris le Jeudi 18 de Febvrier 1558, in Euvres Complètes, éd. E. Balmas, Paris, Gallimard, 2 vol., 1965, II, p. 234. Toutes les références renvoient à cette édition.

${ }^{39}$ Ibid.

${ }^{40}$ Voir par exemple N. Petit, épitaphe de Louis de La Trémouille, dans Bouchet, Panegyric du Chevalier sans reproche, Paris-Poitiers, 1527, citée par Jean Lecointe, « Nicolas Petit, Bouchet, Rabelais : la poétique de Politien du 'cercle de Montaigu' au 'cercle de Fontaine-leComte' », Jean Bouchet, traverseur des voies périlleuses (1476-1557). Actes du colloque de Poitiers (30-31 août 2001) réunis par Jennifer Britnell et Nathalie Dauvois, Paris, Champion, 2003, p. 189.

${ }^{41}$ V. 63-68, «Pièces diverses », Euvres poétiques, éd. G. Demerson-M.M. Fontaine, Paris, Champion, t. 2, 2001, p. 212. 
L'endurance de César permet également à Dorat de suggérer une comparaison avec Guise : lui qui, déjà, n'avait pas tremblé devant les neiges des Alpes, méprisa les frimas d'Iccius, c'est-à-dire de Portus Itius, identifié avec Calais d'où César partit pour la Grande Bretagne ${ }^{42}$ : tandis que le poète célèbre cette qualité militaire et morale, la référence érudite rappelle discrètement le texte du De bello gallico.

Ces atouts ne signifient d'ailleurs pas que César ait bénéficié d'une constitution physique inébranlable: s'appuyant sur Suétone, Baif évoque les crises d'épilepsie dont il souffrait :

On sçait que Cæsar le grand Prince,

Vaincueur de plus d'une province,

Tomboit du haut-mal abatu :

Mais ce mechef rare en l'histoire,

Ne pouvant obscurcir sa gloire

Chét éblouï de sa vertu ${ }^{43}$.

Comme le souligne l'autre version de ce poème dans les Etrenes de Poézie fransoêze, cette faiblesse «du corps» a presque été laissée de côté par «les écrits vieux $\gg^{44}$. Elle contribue donc ici à renouveler l'image de César, rendue plus humaine et imitable. Cette tendance est confirmée par l'accent mis sur sa popularité auprès des soldats. C'est cette qualité que Du Bellay considère comme le ressort majeur de la force de César. Il le rappelle pour mettre en valeur le crédit dont Henri II jouit au sein de l'armée et pour encourager ce dernier, indirectement, à estimer et à cultiver «la foy du François belliqueur»:

Le grand Cesar, qui les Cesars honnore,

Fut de son gendre et du Senat vainqueur

Pour avoir eu de ses soldats le cueur,

Tesmoing Crassin et mille autres encore ${ }^{45}$.

Ce qui importe avant tout, c'est donc, outre la stature d'auteur de César, sa force de caractère et la qualité de sa relation avec ses soldats. Mis à part les quelques vers d'un Belleau marqué par ses souvenirs artistiques, ces poètes s'efforcent donc de ne pas vanter cette terribilità qui séduit tant les rois et une cour pénétrés par les

${ }^{42}$ Jean Dorat, Ode XVIII, De Poetis et Principibus victoribus poetas amantibus. Ad eundem Principem Carolum Lotharingum Cardinalem. Carmen Pindaricum Aurati, ep. 13, v. 296297, Les Odes latines de Jean Dorat, éd. et traduction Geneviève Demerson, ClermontFerrand, Faculté des Lettres et Sciences humaines, 1980, p. 140-141. Sur l'identification du site par Vigenère dans son édition des Commentaires (1576), voir F. Lemerle, La Renaissance et les antiquités de la Gaule, Brepols, 2005, p. 80.

${ }^{43}$ "A Monseigneur Louis de Gonzague, duc de Nevers», v. 31-36, Le Settieme Livre des Poemes, OC, t. I, p. 398. Voir Suétone, César, XLV ; Plutarque, César, 17,2.

${ }^{44}$ Voir Etrenes de Poézie fransoeze en vers mezures, 1574 , Euvres en rime de Ian Antoine de Baïf, éd. Marty-Laveaux, t. V, Genève, Slatkine Reprints, 1972, p. 317.

${ }_{45}$ "Au Roy», v. 1-4, Sonnets divers, STFM, VI, p. 267. Voir Suétone, César, LXVIII ; Plutarque, César, 16,1. 
influences ultramontaines et pour qui, par ailleurs, les armes l'emportent sans nul doute sur les lettres. C'est aussi éviter de développer une dimension qui rapprocherait César du divin, de même que l'on évite à tout prix, semble-t-il, de parler de César magnus Pontifex, réunissant tous les pouvoirs, ou encore de sa clémence à l'égard de ses ennemis politiques.

De tous les poètes de la Pléiade, Baîf nous paraît être celui qui exalte le plus Jules César, même si la figure d'Auguste occupe dans son œuvre une place inégalée. Le point de vue de cet enfant de Venise s'ancre probablement dans un ressentiment aux accents personnels. Pour lui, le personnage de César démontre en effet que, contrairement à ce qu'il perçoit comme l'opinion de la noblesse française, cultivé et pleutre ne sont pas synonymes :

Cæsar fondateur de l'Empire,

Qui sçavoit aussi bien écrire

Comme de la Milice l'art :

Qui renversa tant de murailles :

Qui vainquit en tant de batailles

Le tient-on pour homme couhard $?^{46}$

Aussi César surpasse-t-il même Alexandre, pourtant souvent considéré comme supérieur: après avoir soumis les ancêtres de ces Français qui continuent à mépriser «des Muses le fruit », César a su exploiter leurs qualités militaires pour se rendre maître du monde :

Luy vaillant maistre de la guerre,

Par soudars nez en vostre terre,

Vainquit vos vainqueurs ses Romains :

Sage et sçavant par sa prudance

Bien conduisant vostre vaillance,

Rangea tout le monde en ses mains ${ }^{47}$.

L'amertume se mêle à l'ironie : s'ils ne détiennent pas cet empire universel si convoité, les Français ne doivent donc s'en prendre qu'à leur propre inculture et au manque de sagesse de leurs $«$ doctes chefs ${ }^{48}$.

Cependant, les autres poètes de la Pléiade ne l'entendent pas exactement ainsi. Bien sûr, glissant de César/Charles Quint à Jules César, c'est à François de Guise, bras du roi de France, que Du Bellay rend, en janvier 1558, «de Cesar la prompte vigilance $»^{49}$, habituellement attribuée à l'Empereur. L'occasion est belle aussi, pour traduire en français le fameux Veni, vidi, vici:

Ce que, parlant de soy, Cesar mesme disoit,

Cetuy-cy le peult dire à bon droict (ce me semble)

\footnotetext{
${ }^{46}$ «A Monseigneur de Saint Suplice», V. Livre des Passetems, OC, t. IV, p. 443.

${ }^{47}$ Ibid.

${ }^{48}$ Ibid.

${ }^{49}$ Du Bellay, Hymne au Roy sur la prinse de Callais, 1558, v. 89 et 96-99, STFM, VI, p. 27.
} 
Je suis venu, j'ay veu, j'ay vaincu, tout-ensemble ${ }^{50}$.

Mais le propos de Du Bellay répond avant tout à la convenance. En effet, la figure de César est à cette époque officiellement associée à la fois au roi de France et à Charles Quint, comme en témoigne une magnifique médaille aux bustes superposés à droite, laurés, de Henri II cuirassé, Charles Quint, Jules César et Lucrèce (fig. $3)^{51}$. Or, à cette date, l'empereur vit retiré à Yuste et l'image de Jules César semble désormais revenir au seul roi de France.

En fait, depuis le siège de Metz en 1552, Du Bellay, poète rusé, satisfait lui aussi au désir de son souverain : dans «Les tragiques regrets de Charles V empereur », il montre ce dernier rapprochant son sort de celui de Pompée. La figure du vainqueur de Pharsale reste ainsi virtuellement disponible pour Henri II, qui a fait orner son armure de cérémonie d'un magnifique décor historié illustrant les épisodes de la lutte entre César et Pompée. L'esthétique de la représentation de César recevant à Alexandrie la tête de Pompée, sur la plaque gauche du plastron, exprime une éthique où la volonté moderne d'exprimer la terribilità, la terreur sacrée, soutenue par la référence humaniste et l'antique tradition de l'ornementation des armes, ne contrevient pas aux idéaux de la chevalerie, encore vivants (fig. 4) ${ }^{52}$. Cependant, dans son poème, Du Bellay s'abstient de nommer César: s'il le faisait, ne serait-ce susciter aussi l'image du dictateur assassiné par ses proches? Les sous-entendus d'une épigramme Ad Carolum Caesarem, publiée après la mort de Charles-Quint, permettent de le penser :

Coesareum tibi sit fecit foelici sidere nomen

Carole, nec fatum sit tibi Coesareum ${ }^{53}$.

Un autre poème, dédié cette fois à Diane de Poitiers, joue, comme tant d'autres pièces, de l'ambiguïté onomastique entre César/Charles Quint et Jules César. Un concetto souligne combien, pour sa part, Du Bellay préfère proposer pour modèle au roi Auguste qui «rend le siècle heureux », et non un sombre

Cesar odieux

Aux hommes et aux dieux ${ }^{54}$.

\footnotetext{
${ }^{50}$ Hymne au roi (...), v. 96-98, op. cit., VI, p. 27.

${ }^{51}$ Jacques II Rouaire, sans revers, Br. Et Br. doré. Cab. De France. Voir F. Mazerolle, Les médailleurs français du XV siècle au milieu du XVII siècle, 3 vol., 1902-1904, Paris, Imprimerie Nationale, 1904, t. I, p. LXXXIX et T. II, p. 63, nº 297, T. III, pl. XIX, nº 297.

${ }^{52}$ Musée du Louvre, MR 427. Voir Bruno Thomas, «Les armures de parade des Rois de France », L'art de Fontainebleau, Paris, CNRS, 1975, p. 57 sq. ; Jean-Pierre Reverseau, «Les armes personnelles de Henri II », Henri II et les arts, Paris, Ecole du Louvre, 2003, p. 93-102.

${ }_{53}$ "Que le nom de César te soit de bon augure, Charles, et puisse ton destin ne pas être celui de César », Ad Carolem Caesarem, Varia Epigrammata, (Ep. 23), trad. G. Demerson, STFM, VII, 1984, p. 96-97.

${ }^{54}$ V. 152 et 161-162, Poésies diverses, STFM, V, p. 373 et 374.
} 
Néanmoins, Charles IX n'hésite pas à accepter cet héritage historique et imaginaire. La médaille du sacre, en 1561, par exemple, et surtout celle frappée pour son Entrée en Avignon, le 30 septembre 1564, permettent même de penser que le personnage de Jules César enthousiasme ce roi encore enfant : non seulement César figure au nombre des neuf Preux qui l'accueillent en lui souhaitant de devenir le dixième d'entre eux ${ }^{55}$, mais la ville lui offre une très belle imitation de monnaie romaine où son effigie est stylisée en Jules César (fig. 6) ${ }^{56}$.

Ronsard et Dorat répondent alors eux aussi au voeu du souverain et à cette iconographie officielle, tout en orientant le propos vers un plaidoyer pro domo: ils souhaitent au jeune roi de faire preuve des qualités militaires, intellectuelles et d'écrivain de César et surtout de perpétuer sa politique culturelle, poursuivant ainsi l'accomplissement de la translatio studii et imperii. Nommer César dans un appel au mécénat, avec Alexandre ou Auguste, constitue alors un topos ${ }^{57}$ et, dans son élégie de 1567 «Au Roy Charles IX », Ronsard formule le vœu qu'il devienne un souverain

Qui de la main, en laquelle il aura

L'estoc sanglant, en sa tente escrira

Comme un Cesar, des livres, dont la gloire

Des ans veinqueurs combatront la victoire,

Portant au front deux replis de Laurier

Pour estre ensemble et sçavant et guerrier :

Car pour bien faire, il faut qu' un Roy se serve

De l'une et l'autre excellente Minerve ${ }^{58}$.

Réactualisant le topos sapientialfortitudo mis en scène dans l'Ignorance chassée, cette image s'inscrit dans une logique de continuité dynastique. Elle répond parfaitement à celle de Charles IX dans un dessin d'Antoine Caron en 1562 dans L'Histoire de la Royne Artémise: le jeune roi y reçoit le livre et l'épée ${ }^{59}$.

Cependant, avec les guerres de religion, les réticences s'accentuent. En effet, dès 1561 , César est rendu à la vie en tant que personnage de théâtre par Muret et Grévin : au lendemain de la conjuration d'Amboise, le poète protestant le fait mourir en français sur la scène du théâtre de Beauvais et considère cette mort comme

\footnotetext{
${ }^{55}$ Voir ci-dessus note 1.

${ }^{56}$ Tête à droite de Charles IX lauré, avec l'inscription CAROLO.IX.FRANC.REGI. Au revers, vue de la ville d'Avignon. En haut du champ: AVENIONIS. En bas du champ : MVNVS. VoIR F. Mazerolle, Les médailleurs français, $d u X V^{e}$ siècle au milieu $d u X V I I^{e}$, Paris, Imprimerie Nationale, 1902, 2 vol., t. III, pl. XX, n 355 et notice t. I-II, p. 75 . Voir aussi, notamment, la médaille du sacre, ibid., pl. VIII, $\mathrm{n}^{\circ} 127$.

${ }^{57}$ Voir par exemple Dorat, «In laudem picturce », Pöematum liber tertius, in Poëmatia, Paris, Linocier, 1586, 2 vol., désormais abrégé P., t. I, p. 197.

${ }^{58}$ «Au Roy Charles IX», v. 123-130, le Bocage Royal, t. II, p. 44.

${ }^{59}$ Caron peindra cette scène vers 1575 dans La Remise du Livre et de l'Epée. Voir présentation et reproductions dans Jean Ehrmann, Antoine Caron, Paris, Flammarion, 1986, p. 79-81 et p. 44 et 66 fig. 24, p. 46-47, fig. 26.
} 
l'exemple même du fait tragique selon Aristote ${ }^{60}$. Aussi, Dorat dédiant après 1568 son Proesagium in Historiam Guichardini au jeune Charles IX souhaite-t-il que ce dernier fasse de Lutetia à la fois une nouvelle Troie et une nouvelle Rome. Mais tandis qu'il évoque la gloire de Rome, que des expressions comme Tu quoque constituent autant d'allusions à Jules César et qu'il aurait été facile de rapprocher les deux descendants de Iulus puisque, dit-il, Charles IX descend de lui à la fois par son père et sa mère, Dorat évite, lui aussi, de mentionner Jules César ${ }^{61}$.

Jodelle fait également preuve de subtilité, surtout lorsque les circonstances offrent une excellente occasion d'évoquer César pour rappeler au Prince son devoir envers la nation. Par exemple, l'image du glorieux vainqueur apprenant la mort de sa fille alors qu'il se trouvait géographiquement très éloigné d'elle offre un excellent modèle parénétique à adresser aux Grands frappés par le deuil. Le poète s'en souvient en 1568 dans un sonnet à Catherine de Médicis «Sur la mort de la Royne d'Espagne sa fille aisnée »:

La fille à ce Cesar qui peut jadis conquerre

Nos Gaules en dix ans, par mort avoit rendu

Le tribut de nature : or du pere entendu

Fut tel trespas alors qu'il domtoit l'Angleterre $(\ldots)^{62}$

Ce rapprochement est d'autant plus habile que le défunt Henri II avait précisément choisi la scène de la mort de Julia pour orner le devant du ventail de son casque d'apparat (fig. 5). D'autre part, une discrète allusion au De Bello gallico honore la culture de la reine : Jodelle souligne cet éloignement par une parenthèse à la fois historique et étymologique faisant intervenir le blanc, couleur aussi du deuil. Il évoque

(L'Angleterre qu'il [César] nommoit Albion pour la terre Qui de loin paroit blanche $)^{63}$.

Mais la consolation que Jodelle entend prodiguer passe surtout par le rappel que les malheurs de la vie privée ne doivent pas affaiblir les Grands : dans leur cas, la raison d'État prime sur tout. En dramaturge, il fait revivre César en lui rendant, au style direct, une parole qui oppose une réaction politique à l'abattement du deuil. Il réussit, en français, une formule lapidaire parfaitement respectueuse de la concision

\footnotetext{
${ }^{60}$ «La Tragédie donc (comme dit Aristote en son art poëtique) est une imitation ou représentation de quelque faict illustre et grand de soymesme, comme est celuy touchant la mort de Jules Cesar», Brief discours pour l'intelligence de ce theâtre, Théâtre complet et poésies choisies de Jacques Grévin, éd. L. Pinvert, Paris, Garnier, 1922, p. 6.

${ }^{61}$ «Tu quoque nunc Phrygio qui par pubescis Iulo,/Dignus Iuleum es bis tenuisse decus./Roma fuit quod Troia: Lutetia a te duce fiet/Et Troia, et quicquid Troica Roma fuit », Ioannis Aurati lemovicis poetce et interpretis Regij Epigrammatum, P., t. II, p. 307.

${ }^{62}$ Sonnet V, v. 1-4, Sur la mort de la Royne d'Espagne sa fille aisnee [1568], OC, t. I, p. 210.

Voir Plutarque, César, 23,6.

${ }^{63}$ Ibid., v. 5-6.
} 
de César et exprimant clairement sa volonté de ne pas se laisser atterrer par le destin :

(...) Adonc fut respondu

Par luy, Morte ma fille et mon gendre perdu :

Mais il ajoute aussitôt : «Aussi le gendre et luy tost apres feirent guerre $»^{64}$.

Par delà le propos de circonstance, il s'agit en effet de recommander à Catherine une politique de conciliation. La guerre civile entre le beau-père et le gendre est évidemment un exemple à fuir. La leçon est claire : la reine doit maintenir l'alliance avec son gendre Philippe II, qui la respectera non par amour filial mais pour des raisons religieuses et stratégiques.

\section{"Cesar odieux»}

En effet, si les qualités de César sont mises en valeur par des pièces encomiastiques appréciées des Grands, l'engouement de la cour pour la terribilità du dux ne fait pas oublier à ces poètes les guerres civiles à Rome et la conquête subie par les ancêtres, surtout à l'heure où les relations avec Rome et les Italiens s'avèrent complexes et où les troubles religieux entrent dans leur phase la plus violente. Elles fournissent l'occasion de contester une image de Rome et de César trop idéalisée et trop centrale, de développer la rhétorique du blâme, comme le recommandait déjà Érasme pour y entraîner les enfants tout en leur assurant une formation morale ${ }^{65}$, et de réfléchir sur la fin du vainqueur et la vanité humaine. L'idée de prendre ainsi une revanche, même très tardive, sur César ou sur les ennemis que l'on assimile à lui, soutient le processus. Peletier résume le premier ce ressentiment :

Ce Cæsar nous a lessé de jolis memoires de ce qu'il a fait en Gaule par l'espace de dix ans : mais je voudrois que s'eust esté Caton, non luy, qui eust escrit ces memoires. Nous en sçaurions des meschancetés qu'il a faites a nostre pauvre païs, mais il en a esté puny ${ }^{66}$.

En 1552, Dorat célèbre en latin la victoire de Condé sur Charles Quint. «Cæsar» renvoie à la fois à l'Empereur et à Jules César et, pour décrire Louis de Condé pro Rege sua arma ferentis/Contra Caesareas (...) phalanges (...) cohortes, le poète reprend les termes mêmes du De Bello gallico. Malicieusement d'ailleurs, l'index signale Coesar victus a Gallis ${ }^{67}$, tandis que le poème, rappelant les expédi-

\footnotetext{
${ }^{64}$ Ibid., v. 6-8.

${ }^{65}$ Voir Le plan des études, op. cit., p. 457.

${ }^{66}$ Discours non plus melancoliques, op. cit., p. $43 \mathrm{r}^{\circ}$ et $\mathrm{v}^{\circ}$. Cette position des Français cherchant à partir du personnage de César à nier la position centrale de Rome n'est pas nouvelle. Elle est notamment évoquée dans les années 1370 par Pétrarque dans le De gestis Cesaris.

${ }^{67}$ De felicissima Gallorum victoria ad Cariniacum parta, ductu Strenuiss. Principis Ducis Anguiani, Ad Illustr. Cardinalem Borbonium,Paris, t. I, p. 83 et 86.
} 
tions de César contre les Helvètes et les Germains, affirme la bravoure et la victoire des Français, ces Gaulois des temps modernes ${ }^{68}$.

La même année, Tyard va plus loin: dans la dédicace de Solitaire Premier, c'est la réputation même de l'homme de guerre qu'il attaque, probablement plus «fabuleuse », dit-il, que celle de Camille, d'Arpalice ou des Amazones et associée à celle de «la centeine des neuf Preux ${ }^{69}$. De même, dans un sonnet adressé en 1557 à Marguerite de France après Saint Quentin et avant la reconquête de Calais, Jodelle n'hésite pas à invectiver César pour stigmatiser le mépris qu'il avait affiché à l'encontre des Gaulois venus se réfugier auprès de lui de peur d'Arioviste. Il entend démentir la présomption de servilité que César fait peser sur eux et, retournant contre l'ennemi les accusations de lâcheté, proclamer le courage des Français devant les vicissitudes de la guerre :

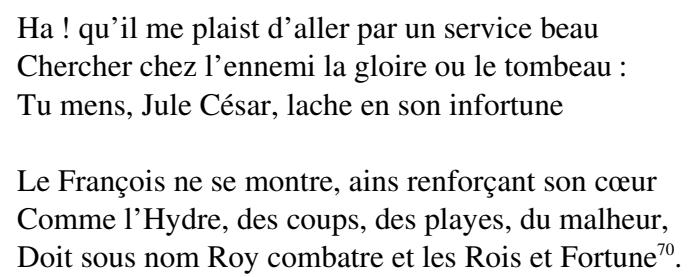

On critique aussi, d'un point de vue politique et moral, l'excessive ambitio de Jules César. Elle résulte de l'exécrable envie s'emparant, selon Aristote, de ceux qui se «sont illustrez et anobliz par actes genereux» et qui pensent «que celluy qui les suyt, leur veult arracher l'honneur sur lequel il a desja mis la main ${ }^{71}$. Pompée, Marius et Silla en constituent les autres paradigmes. C'est à cause de cette ambition qu'on lui attribue seulement le second rang, après Alexandre le Grand. Ainsi, lorsque Jodelle montre Henri II en Alexandre, réservant à ses «neveux » l'image de César pleurant d'être inconnu à l'âge où le Macédonien était couvert de gloire, la raison n'est pas seulement d'ordre chronologique ${ }^{72}$. Cependant, les excès de César fournissent aussi aux poètes de nouveaux arguments. Ils permettent par exemple d'écrire que les grands soldats de la France lui sont supérieurs et, ici encore, de plaider en faveur de la modération.

Dans «Le Retour d'Anne de Mont-morency Connestable de France » d'abord publié en 1559, Ronsard tresse l'éloge du principal négociateur du traité de Cateau-

\footnotetext{
${ }^{68}$ Voir par exemple: Villofrancus iens terfo iubet exeat ordo/Ad frontem geminus, sic ars deluditur/Nudaque iam virtus accerrima pugnat utrinque,/Fracti Casari cedunt tamen, haud sine Galli/Militis auxilio, cui Buterus antè prcebat., ibid., p. 87-88.

${ }^{69}$ Pontus de Tyard, Euvres, Solitaire Premier, éd. S. Baridon, Genève, Lille, Droz, Giard, 1950, p. XXI.

${ }^{70}$ Sonnet III, v. 9-14, «A Madame Marguerite, sœur du Roy Henry deuxiesme, depuis duchesse de Savoie », OC, t. I, p. 175. Voir César, De Bello Gallico, I, 30-31.

${ }^{71}$ Ronsard, De l'envie, Pièces françaises en prose, t. II, p. 1196. Voir Aristote, Rhétorique, II, $\mathrm{X}, 3$.

${ }^{72}$ Christianorum Nostri Temporis Heroum, et Heroinarum Icones, OC, t. I, p. 188. Voir Suétone, César, VII ; Plutarque, César, 11, 6.
} 
Cambrésis. Sa «vertu » dépasse celle des «belliqueux Romains »: le sage Scipion ne saurait l'égaler,

Ny le premier Cæsar qui mist dessous sa main

Par trop d'ambition tout l'Empire Romain ${ }^{73}$.

Mais la critique se fait beaucoup plus virulente lorsque Jules César sert à dénoncer les généraux sanguinaires et les tyrans politiques. En 1547, Peletier avait publié la traduction du Livre I des Géorgiques, qui évoquent de façon réaliste les pertes subies aux deux batailles de Pharsale, déplorant que

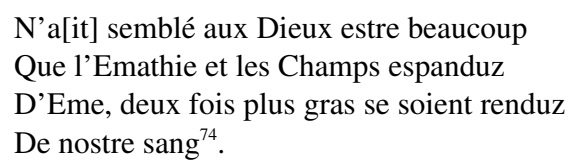

Une telle violence semble caractéristique de l'antiquité. Elle contrevient aux principes du christianisme. Lors de la trêve de Vaucelles conclue par Henri II avec Charles-Quint et Philippe II le 5 février 1556 (n.s.), Du Bellay, dans un plaidoyer en faveur de la paix, remercie le roi de s'être

(...) souvenu d'estre Roy Treschretien :

Non un Jules Cesar, un Pyrrhe, un Alexandre,

Qui ne prenoient plaisir qu'à sang humain espandre ${ }^{75}$.

Dans les Antiquitez de Rome publiées en 1558, deux ans après l'abdication de Charles Quint, il médite à travers quatre sonnets sur le rôle de Jules César et des guerres civiles dans l'histoire de l'empire romain. Du Bellay ne nomme pas César: cela contribuerait à le grandir. Il préfère l'évoquer indirectement, le ramenant ainsi à la dimension d'élément constitutif mais non exceptionnel de l'histoire de Rome, de paradigme offert à une méditation politique et morale destinée à l'instruction des hommes du XVI siècle. Dans l'évolution qui a conduit Rome du pouvoir des pasteurs à la royauté puis à l'empire, pour finalement revenir au pouvoir d'un pasteur, le Pape (sonnet XVIII), César signifie le temps de la dictature qui succède au consulat et constitue le maillon permettant le passage à l'empire. Du Bellay s'appuie sur Tacite :

${ }^{73}$ V. 85-86, Le Second Livre des Poemes, t. II, p. 820. Si l'on considère que l'apothéose du triomphe d'Alphonse V d'Aragon a consisté en l'apparition d'un char avec Jules César couronné de lauriers élevé sur un globe terrestre qui tournait sur lui-même, image diffusée par Giovio puis Simeoni (voir ci-dessus note 9), il nous semble plausible de comprendre qu'il s'agit ici de Jules César. Voir aussi Grévin, qui compare l'ambition de Charles Quint à celle de César : "Ainsi le feu de Iules ne print cesse/Tant que la mort le priva de tristesse », Les Regretz de Charles d'Autriche, empereur cinquiesme de ce nom (...), Paris, M. L'Homme, 1558, p. [17].

${ }^{74}$ «Le Premier Livre des Georgiques de Virgile», Euvres poétiques, éd. L. Séché et P. Laumonier, Genève, Slatkine reprints, p. 71.

${ }^{75}$ Discours au Roy sur la trêve de l'an M.D.LV, v. 147-149, STFM, V**, p. 11. 
Puis l'annuel pouvoir le plus grand se vid estre,

Et fut encor plus grand le pouvoir de six mois :

Qui, fait perpetuel, creut en telle puissance,

Que l'aigle Imperial de luy print sa naissance ${ }^{76}(\ldots)$

César incarne aussi l'orgueil et l'ambition qui s'emparèrent de Rome après les guerres puniques (sonnet XXIII). La «civile fureur», comme le soulignait déjà en français Le livre de police humaine de Gilles d'Aurigny, en $1546^{77}$, rompt les unions les plus sacrées, déchire les familles mêmes,

Ce qui advint, quand l'envieux orgueil

De ne vouloir ny plus grand ny pareil

Rompit l'accord du beaupere et du gendre ${ }^{78}$.

Coupables de la ruine de Rome, César et Pompée apparaissent alors comme les actualisations dans l'histoire du «cruel destin» ou d'un «vieil péché » dont la vengeance se manifeste par une discorde contraire à la justice divine, l'Homme régressant à un état inférieur à celui de l'animal. Les passions qui se déchaînent modèlent l'histoire, individuelle et collective. Source de malheur, elles entraînent une diminution de l'autorité politique et déstabilisent l'État (sonnet XXIV) ${ }^{79}$. Ce péché, version chrétienne de l'hybris, le poète le dénonce à nouveau (sonnet XXXI) : c'est l'orgueil qui a conduit à la guerre civile. La bataille de Pharsale en résume toute l'horreur:

Tu en es seule cause, ô civile fureur,

Qui semant par les champs l'Emathienne horreur,

Armas le propre gendre encontre son beaupere ${ }^{80}(\ldots)$

Quelques années plus tard, tandis que les guerres de religion font rage, Ronsard noircit encore César dans les Prognostiques sur les miseres de nostre temps. Modèle de l'un de ces inconnus aux discours frénétiques et prémonitoires qui erraient dans les villes juste avant qu'éclatent les troubles, César devient menace immédiate, signe apocalyptique :

Un qui crioit, enflé de hardiesse,

La Monarchie, et Cesar se vantoit

\footnotetext{
${ }^{76}$ Sonnet XVIII, v. 7-10, Les Antiquitez de Rome, STFM, II, 1927, désormais abrégé AR, p. 19. Voir également Tacite, Ann., I, I, et Dante, Banquet, IV, v, 12 I.

77 «Les Rommains ont esté tousiours seigneurs de l'Empire du monde, tandis qu'ilz furent en union et paix ensemble, et qu'ilz se sont abstenus de sang civil et de guerre intestine. Mais après (...) les armes du gendre et du beau pere, c'est à sçavoir Iules Cesar et Pompée (...) les Romains (...) tomberent en derision et mocquerie du peuple et des ennemys barbares », Le livre de police humaine, Paris, L'Angelier, 1546, p. $72 \mathrm{v}^{\circ}-73 \mathrm{r}^{\circ}$.

${ }^{78}$ Sonnet XXIII, v. 12-14, AR, op. cit., p. 17.

${ }^{79}$ Ibid.

${ }^{80}$ Sonnet XXXI, v. 9-11, ibid., p. 28.
} 


\begin{abstract}
Vint apres lui : il disoit qu'il estoit Ce grand Cesar, qui au fil de l'espée Par sang civil baigna Rome et Pompée. $\mathrm{Ce}$ fol estoit de nation romain.

(...)

Lors je disois tout pensif en moy-mesme :

Assez et trop nostre France a de fouls

Sans que le Tybre en respande sur nous :

Sans nous donner un Cesar, qui l'Empire

Fist tresbucher, et qui nous vient predire

Un changement ou d'estat ou de lois ${ }^{81}$.
\end{abstract}

Jules César se trouve donc au cœur de la réflexion sur la déstabilisation politique, l'ingérence étrangère et la guerre sous toutes ses formes, causes, exactions, conséquences. Alléguer son exemple permet aux poètes de proclamer et de justifier leur opposition vis-à-vis de tous ceux qui, comme lui, font couler le sang des «Gaules », Charles Quint aussi bien que les fauteurs de troubles civils.

On lui reproche également d'avoir été le fossoyeur de la liberté. Mais il n'est pas ici question de cette servitude sucrée évoquée par La Boétie dans le Discours de la servitude volontaire: Du Bellay compte Brutus au nombre des héros romains ${ }^{82}$ et Tyard rappelle que Caton d'Utique se suicida en 46, ne voulant survivre à la République après la défaite de Pompée. Comme Dante, il salue «Le grand Romain qui aima mieux s'occire,/Que vivre serf ${ }^{83}$. Et dans une épigramme sur la relation omen/nomen dans le nom de Julius, tantôt excellent, tantôt exécrable, Dorat martelle à partir du Coesar et omnis Iuli progenies de l'Énéide ${ }^{84}$ des vers lapidaires contre César destructeur de la République :

Rem Romulam Troianus olim condidit Iulus Aenea satus.

Rem Romulam Romanus olim perdidit

Patrice tyrranus Iulius ${ }^{85}$.

\footnotetext{
${ }^{81}$ «Prognostiques sur les miseres de nostre temps », v. 28-31 et 34-39, t. II, p. 1040.

82 «Les Furies contre les infracteurs de Foy », v. 78, STFM, VI, p. 146.

${ }^{83}$ Sonnet XXX, v. 12-14, Premier Livre des Erreurs amoureuses, Euvres poétiques complètes, éd. J.C. Lapp, Paris, STFM, 1966, p.42. Voir Dante, Purg. I, 70-75.

${ }^{84}$ En. VI, 789.

${ }^{85}$ « Ad Iulium P.M. », Epigrammatum Lib. I, P., t. II, p. 16. Geneviève Demerson signale un texte manuscrit, probablement postérieur, où Dorat attaque le pape Jules III, qui « eut en commun avec Jules César des mœurs contre nature et le goût des bouleversements politiques », Dorat en son temps, Clermont-Ferrand, Adosa, 1983, p. 290, n. 126.
} 
César est ainsi l'origine d'une lignée de «Juliani » les uns excellents, les autres sinistres, dont le poète souhaite qu'elle se termine avec le nouveau pape Jules III, qui guérira l'Église ${ }^{86}$.

D'un côté, on veut donc espérer que les temps modernes représenteront un progrès moral et politique par rapport à l'antiquité. De l'autre, déjà sous Henri II, la cour de France apparaît comme un lieu de régression où, selon Jodelle, «l'un se fait ou Cresus, ou Crassus $»^{87}$. Mais c'est la puissance destructrice des guerres de religion qui suscite plus que tout l'image d'un César symbole de la violence antique. En 1581, Peletier déplore celles

Qui ont les Rois et les Etats defaits,

(...)

Et à la fin les trionfans Romains ${ }^{88}$.

Ces critiques conduisent à l'expression d'une peur générale et, à partir des Vies de Plutarque, à une réflexion sur la condition humaine. Comme Alexandre, César offre un exemple de l'injustice attachée à «l'honneur que l'homme espere de la guerre ». Seul en effet le grand capitaine bénéficie de la renommée attachée aux batailles gagnées grâce au courage de tant d'autres :

Et de tous ceus par qui César veinquit

$\mathrm{Nul}$, fors que lui, la gloere n'an aquit ${ }^{89}$.

S'il n'est pas immérité, l'honneur de la victoire est toutefois éphémère. Lorsque revient la paix, il se voit en effet contesté car, entraînant souvent une perte de tout sens moral et religieux, il conduit à des exactions suscitant la vengeance. Peletier, qui dans son Art poétique admirait Virgile d'avoir montré «les faits humains, être alternatifs avec adversité et felicité ${ }^{90} »$, présente César comme le généralissime puni d'avoir semé, après la victoire, la division dans son propre peuple, de l'avoir combattu et d'avoir favorisé le règne de la traîtrise :

Cesar veinqueur des puissances Galiques,

Qui deploya tant d'anseignes belliques

Ayant veincu son Peuple desuni,

Du sang Civil, an son sang fut puni ${ }^{91}$.

\footnotetext{
${ }^{86}$ «Ut Iuliis, sic Iuliorum posteris,/Quos Iulianos nominant,/Par nomen est dispar, sed omen nominis/Huic optimum, illi pessimum./Ecclesiam nam Iulianus perdidit/Apostolarum signifer./At perditam nunc restituis ecclesiam/Medica Iuliane tu. », ibid.

${ }^{87}$ «Epithalame de Madame Marguerite (...)», OC, t. II, p. 175.

88 «Louange de l'Honneur», Euvres poetiques de Iaques Peletier du Mans intitulez Louanges (...), Paris, R. Coulombel, 1581, p. 30 r $^{\circ}$.

${ }^{89}$ Ibid., p. $30 \mathrm{r}^{\circ}$.

${ }^{90}$ Art poétique, 1555 , p. 307.

${ }_{91}$ «Louange de l'Honneur», op. cit., p. $31 \mathrm{r}^{\circ}$.
} 
La leçon politique nourrit une réflexion philosophique sur l'importance de la mesure et du contrôle de soi. César y rejoint d'autres personnages excessifs, Hector, les rois de Perse, Pompée ou Charles le Téméraire :

Einsi trop d'eur, l'Homme vient aveugler,

Qui ne le sait moderemant regler ${ }^{92}$.

\section{"J'admirais de Cesar l'image venerable»}

Cette réflexion se poursuit en méditation sur la volonté face à la force du destin, la responsabilité et l'erreur, indissociable de la condition humaine: malgré sa «vigilance», l'homme est par essence sujet à la faute. La perfection lui est impossible et nul n'est maître de la Fortune. Les défaites des Romains considérés a priori comme les plus forts le montrent bien : à l'exemple de la bataille de Cannes vient s'ajouter celui de la victoire de Pompée en 48 , où

Presque Cesar a Dirrache perdit

Anvers Fortune, es Armes son credit ${ }^{93}$.

César s'inscrit en effet aussi dans une lignée d'illustres capitaines qui, en dépit de leur volonté et de leur prudence, n'ont pu éviter pour eux-mêmes ou pour leur patrie des désastres, présents ou futurs: Thémistocle prévoyant que le danger viendrait de Sparte, Sertorius assassiné par des Romains jaloux, Charlemagne perdant Roland.

Il demeure donc un grand personnage, à ce titre et à d'autres : félicitant Grégoire XIII de la réforme du calendrier, Dorat rappelle que Jules César a lui aussi imposé une réorganisation du calcul du temps quotidien en introduisant à Rome, en 46 av. J.-C., l'année de trois cent soixante cinq jours et demi ${ }^{94}$. Et lorsque Tyard veut citer Diodore de Sicile et s'assurer que l'on ne le confonde pas avec un autre, c'est Jules César qui constitue la référence permettant de situer toute cette époque ${ }^{95}$.

Le respect lui est donc dû, comme le montrait aussi Peletier en 1555. Dans l'Art poétique, il critique en effet le style de Lucain dans La Pharsale: d'abord parce qu'il considère que «l'histoire est le Sujet le moins propre pour un Poète (...) Et partant bien a dit Quintilien de Lucain, qu'il est plus à compter entre les Orateurs

\footnotetext{
${ }^{92}$ Ibid.

${ }^{93}$ Ibid., p. $32 \mathrm{r}^{\circ}$.

94 "Tertius accessit cum Coesar Iulius ille,/Quarto cuique anno substituitque diem./Sed qui Pontifices paganos te Numa, teque/Et sacris superet, Coesar, et arte Poli./Gregorius decimus tertius (...) /Namque decem luces de Cosaris abstulit anno (...) », "In perpetuum anni cursum Gregorii XIII summi Pontificis auspiciis emendatum », Pöematum liber tertius, P., t. I, p. 299. Voir Suétone, César, XL.

${ }^{95}$ Nolim equidem affirmare, nulla nobis esse nata domi, neque aliunde petita : monet enim me refricata memoria, Diodorum antiquum et Iul. Casaris contemporaneum historiographum hoc de Gallis scripsisse (...), De recta nominum impositione, A Ponto Tyardceo Bissiano, Lyon, J. Roussin, 1603, p. 17.
} 
qu'entre les Poètes ${ }^{96}$. Ensuite et surtout, parce qu'il juge les évocations de Lucain contraires au decorum :

Je ne veux point ici que Lucain soit pris pour un grand Poète (...) pour ce qu'il est (...) ne gardant point le bienséant des personnes, faisant parler un Nautonier ou quelque homme ignoble (quelles personnes encore ne doivent quasi point être introduites en un Euvre Heroïque) d'aussi grand respect, comme un Cesar ou un Pompée ${ }^{97}$.

Cependant, lorsque Peletier énumère les principales «figures poétiques », il n'hésite pas à se référer à La Pharsale pour fournir un exemple des prosopopées, notamment au passage plein de grandeur où «la Patrie (...) parle à César : combien encore que ce passage soit plus oratoire que poétique ${ }^{98}$.

Comme pour Alexandre ou Auguste, la «gloire » de César se manifeste en effet également par sa fortune littéraire et iconographique. A une époque où les images se voient contestées, César constitue, dans ce domaine aussi, un argument de poids. Son nom se voit placé au cœur du topos nourrissant le plaidoyer en leur faveur. A Dorat, héritier notamment d'un Lemaire de Belges, César permet de rappeler leur importance dans la stature attribuée aux grands hommes, et donc le rôle capital des artistes et poètes qui jouent un rôle essentiel dans leur façon :

Nam quis Alexander, quis Coesar Iulius, ecquis

Sciret et Augustus, nisi sculpta emblemata, pictce

Extentque effigies, pictisque poëmata verbis ?99

Pour Ronsard également, Jules César est un grand personnage : par ses succès et ses revers, il constitue une pièce essentielle de la méditation sur la destinée et sur l'art. Dans l'Hynne de la Mort, le poète s'interroge sur la vanité de l'humain, le retour à la poussière de ceux qui y avaient réduit tant d'autres :

Sommes-nous plus divins qu'Achille ny qu'Ajax,

Qu'Alexandre ou Cesar, qui ne sceurent pas

Defendre du trespas, bien qu'ils eussent en guerre

Reduite sous leurs mains presque toute la terre ? ${ }^{100}$

Dans l'Hynne des Astres également, l'évocation de la diversité des destins conduit à des considérations sur la Fortune, sur la destinée à laquelle nul ne saurait échapper :

Cestuy comme un Cesar apres avoir rué

L'Empire sous ses pieds, est à la fin tué

${ }^{96}$ Art poétique (1555), chap. I, 3, in Traités de poétique et de rhétorique de la Renaissance, éd. F. Goyet, Paris, Le Livre de Poche, 1990, p. 250.

${ }^{97}$ Ibid., I, 5, p. 261.

${ }^{98}$ Ibid., I, 9, p. 277.

${ }^{99}$ In laudem picturce, op. cit., P., t. I, p. 197.

100 «Hynne de la Mort», v. 93-96, Les Hynnes, II, t. II, p. 603. 
De ses gens et ne peut fuir la destinée
Certaine, qu'en nayssant vous lui avez donnée. ${ }^{101}$

C'est alors que la mission essentielle des images, celle de la mémoire, devient pleinement manifeste :

Contemplant l'autre jour un amas de Medailles

Que la terre couvroit au cœur de ses entrailles,

Ronsard s'émerveille de ce que les grandes figures puissent, grâce à l'art, revoir le jour et, liant le passé au présent, délivrer des enseignements pour l'avenir :

(...) toute chose a son Tour,

La mort après la vie, la vie après le jour :

J'admirais de Cesar l'image venerable,

Et celui de Pompee au destin miserable ${ }^{102}(\ldots)$

Au traditionnel Ubi sunt, Jules César permet, dans ce corpus, d'apporter une réponse à la fois humaniste et moderne: celle de l'art et des images, du discours maîtrisé et contrôlé par des poètes proches de la cour mais soucieux, en des temps de plus en plus troublés, de leur indépendance de jugement. Sous leur plume, les brillantes lignes de force de l'officiel topos s'animent d'ombres choisies avec soin, forçant le regard à réévaluer l'image en laissant de côté certains pans de la doxa. Grande figure idéale de l'équilibre du livre et du glaive, illustrant surtout la force des armes et du discours chevillée à une logique de l'action, de l'extension politique dans l'espace et le temps, matiera convenant au decorum des poèmes encomiastiques et permettant une mise en valeur de l'époque contemporaine, Jules César n'en est pas moins un personnage échappant ici à la divinisation autant qu'au romanesque ou à l'anecdotique et offert au débat philosophique, politique, moral et esthétique. Ses leçons linguistiques, stylistiques et phonétiques passionnent tant pour leur elegantia que pour leur matiera et leur efficacité. Cependant, au désir du roi d'être montré en Jules César, ces poètes n'accèdent qu'avec circonspection. Ils apprécient différemment la terribilità qui lui est attachée et, dans ce corpus, il n'est nulle part question de la réunion entre ses mains des pouvoirs politique et religieux. Si César reste synonyme d'ampleur et d'efficacité, on s'ingénie à vanter presque exclusivement, outre ses vertus littéraires, certaines de ses qualités ramÉnées à l'échelle humaine, imitables et utiles au bien public : force de caractère, rapidité et vigilance, proximité avec les soldats laissant dans la victoire peu de place à la chance, réforme du calendrier.

Mais on ne parle pas de sa clémence. En effet, Jules César signifie avant tout pour la Pléiade le règne de l'hybris et des passions, de l'ambition, les horreurs subies par les ancêtres gaulois, les troubles civils, la tyrannie, l'assassinat et, finalement, la revanche de la Fortune sur la Virtu, bref, toute la violence de l'antiquité païenne, à

\footnotetext{
101 «Hymne des Astres », v. 179-182, Les Hynnes, Appendices, t. II, p. 627.

102 «[Sur une médaille d'Antinoüs »], v. 15-18, Pièces attribuées, t. II, p. 1241.
} 
laquelle on tend à opposer Auguste. La leçon est claire : par des jeux de mémoire, de superposition et parfois par leur subtil silence, ces poètes suggèrent ou dénoncent des analogies avec le temps présent pour réclamer la modération et l'équilibre, pour conduire les Grands et en particulier le roi à une réflexion sur la responsabilité politique et morale et les limites du pouvoir au regard du bien public, et aussi sur la nécessité de favoriser l'illustration de la langue française.À travers César le tyran, il s'agit de jeter l'anathème sur ceux qui voudraient priver les Français de liberté, les entraînant dans de sanglantes tragédies. Pourtant, par sa stature, Jules César demeure un grand personnage suscitant des méditations sur la nature humaine, la valeur du destin et des œuvres, et finalement, face à la mort, sur l'art, garant de mémoire et de vie.

Édith Karagiannis-Mazeaud Université de Strasbourg 


\section{ANNEXE}

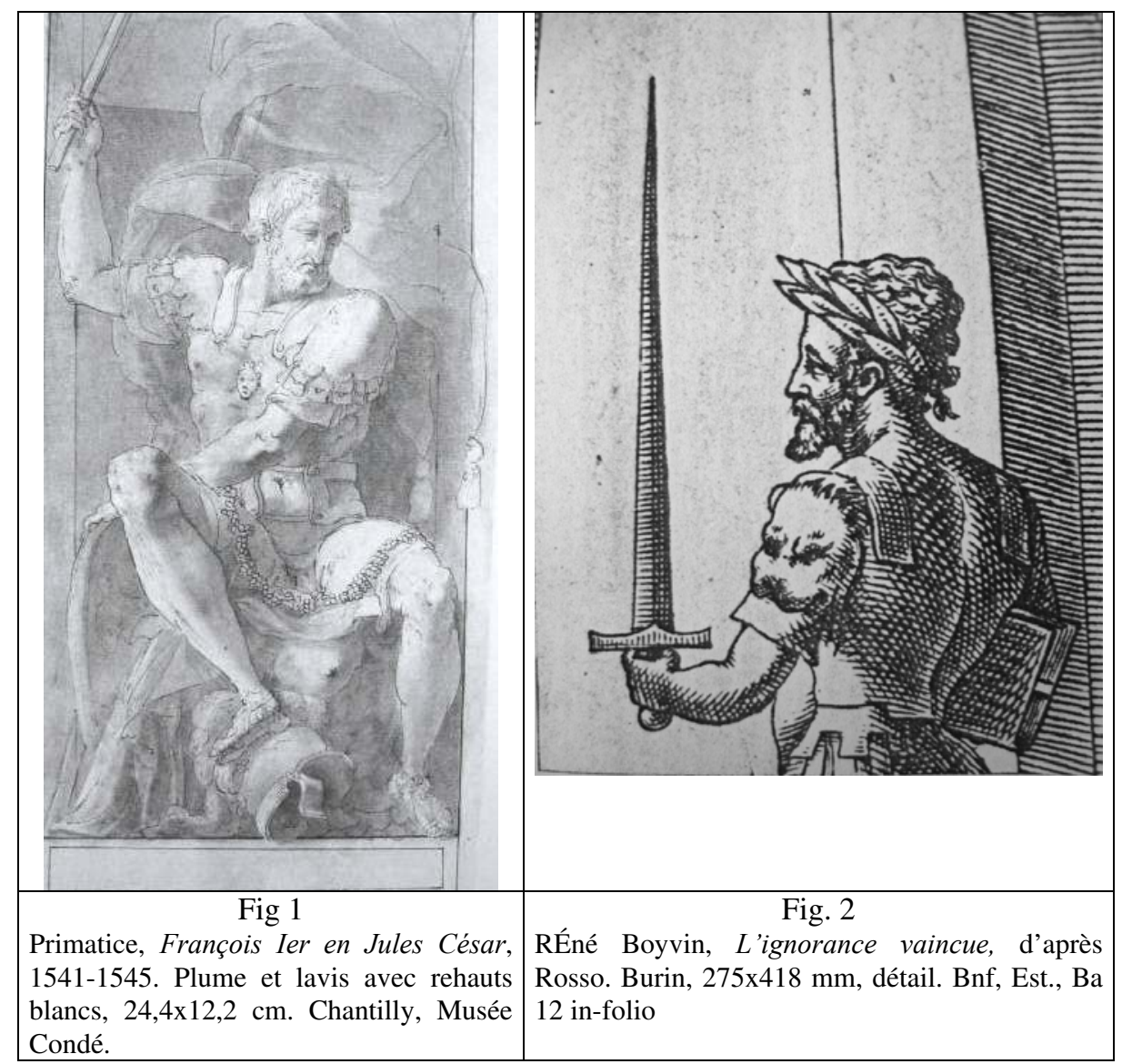



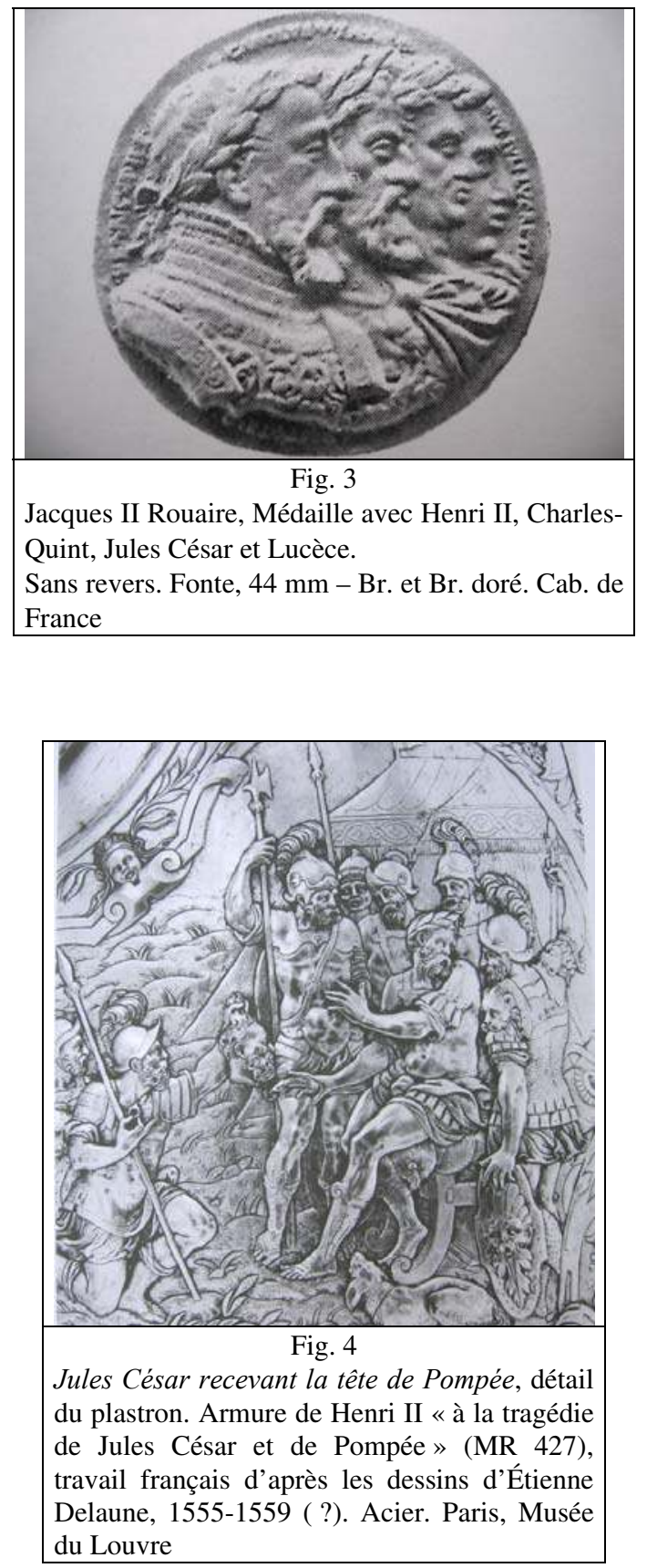

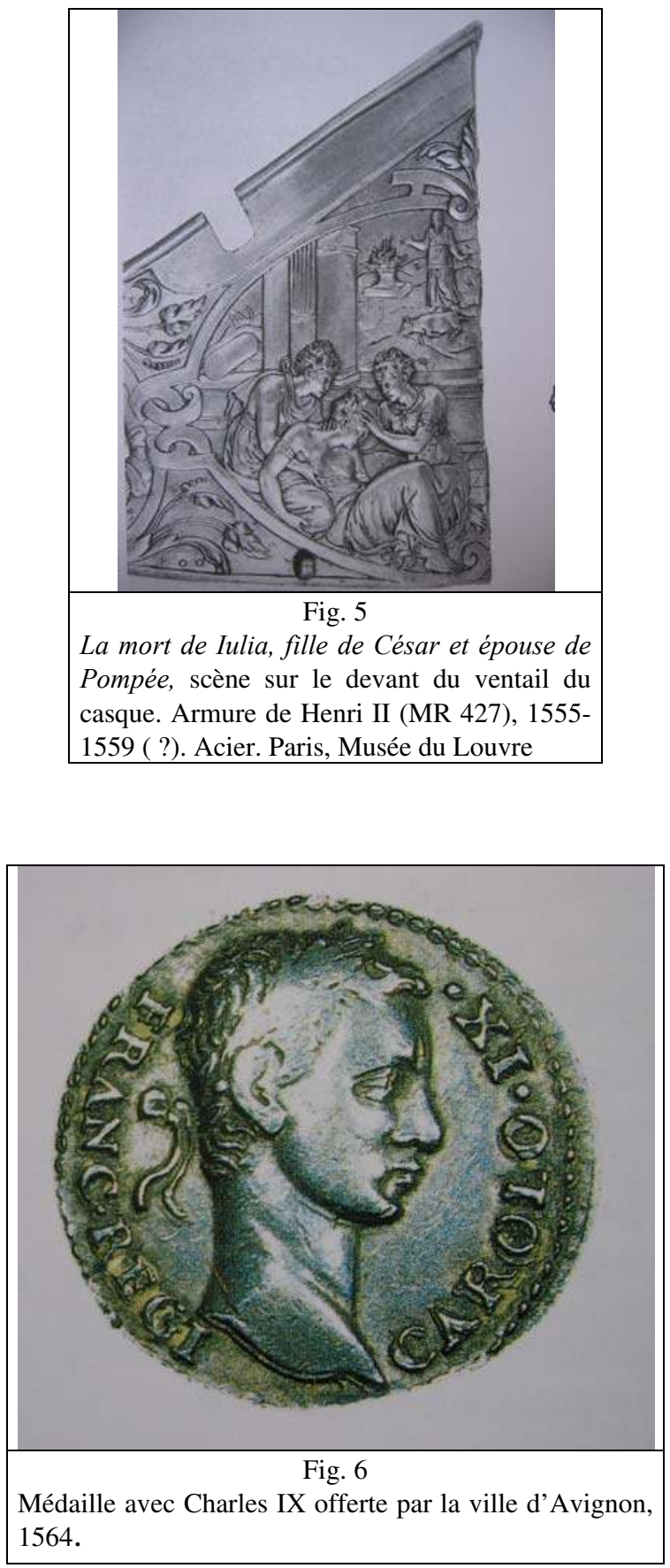